DR THIKRAYAT GH. BANI-HANI (Orcid ID : 0000-0002-0429-8786)

Article type : Original Article

Corresponding author mail id :- anne.oconnell@dental.tcd.ie

Title page

*Manuscript title:

The cost of dental trauma management: a one-year prospective study in children

* Running title:

The cost of dental trauma management in children

\title{
*Authors:
}

Thikrayat Gh. Bani-Hani*, Isabel C Olegário** and Anne C. O’Connell ***

*: Postgraduate Student in Paediatric Dentistry, Dublin Dental School

This article has been accepted for publication and undergone full peer review but has not been through the copyediting, typesetting, pagination and proofreading process, which may lead to differences between this version and the Version of Record. Please cite this article as doi: $\underline{10.1111 / \text { EDT.12561 }}$

This article is protected by copyright. All rights reserved 
${ }^{* *}$ :Assistant Professor in Paediatric Dentistry, Dublin Dental University Hospital, Trinity College, Dublin 2, Ireland

${ }^{* *}$ Associate Professor/ Consultant in Paediatric Dentistry, Dublin Dental University Hospital, Trinity College, Dublin 2, Ireland

${ }^{*} /{ }^{* *}$ (institutional affiliations where the work was conducted)

${ }^{*}$ Corresponding author: Anne C O'Connell

Current affiliations and address:

BA,BDentSc., MS, FAAPD, FIADT

Associate Professor/ Consultant in Paediatric Dentistry

Dept. of Public \& Child Dental Health

Dublin Dental University Hospital - Trinity College Dublin

Lincoln Place - Dublin 2

*Acknowledgement:The authors would like to thank Dr. Erica Donnelly-Swift who provided statistical support to this research. 


\section{Title: The cost of dental trauma management: a one-year prospective study in children}

\section{Abstract}

Background/Aims: Management of traumatic dental injuries (TDI) can be expensive and time-consuming, yet very few studies have addressed the cost of their management. The aim of this study was to evaluate the total cost and the number of visits required to treat dental injuries to permanent incisors in children and adolescents over a one-year period.

Materials and methods: Ninety-five children with at least one traumatic dental injury to their permanent incisors were enrolled and managed according to the International Association of Dental Traumatology guidelines. Injuries were grouped into complex $(n=74)$ and non-complex injuries $(n=21)$ and divided by the date of injury. Total cost was the sum of the direct (capital, staff, materials and laboratory fees) and indirect costs (travel, childcare and missed working hours). All data was collected prospectively through hospital records and questionnaires at each visit over one year. Data was analysed using a linear regression model for the cost and the number of visits. Logistic regression was used to analyse differences between complex and non-complex injuries ( $\alpha=5 \%$ ).

Results: The mean total cost for complex and non-complex injuries was $€ 1687.9$ and $€ 1350.8$ respectively. The treatment of non-complex injuries was cheaper than for complex injuries $(p=0.047)$. The cost of follow up visits 4 years after the injury was significantly lower when compared to the treatment during the first year $(p=0.002)$. Travelling longer distances $(>50 \mathrm{~km})$ for treatment increased the overall cost of the treatment. There was no difference in the number of visits required for complex (mean=5.6) and non-complex (mean=4.9) injuries, but there were significantly fewer visits required in year 4 onwards $(p<0.001)$.

Conclusion: Complex injuries presented a higher treatment cost, but the number of visits required was the same when compared to non-complex injuries over the one year evaluation. Further research in this area is encouraged to add to the limited available data.

*Key words: dental trauma, cost-analysis, children, adolescents, dental injuries 


\section{Main text}

\section{Introduction}

Traumatic dental injuries (TDI) are common with a global frequency of $15.2 \%$ in the permanent dentition ${ }^{1}$, and a global incidence rate of $2.75 \%$ per year in the permanent dentition ${ }^{1}$. The reported prevalence in the permanent dentition ranges from $6 \%$ to $34.8 \%$ in children and adolescents ${ }^{2}$ and the yearly incidence of TDI in the permanent dentition ranges from $1 \%$ to $3.3 \%$ in the $7-15$ year old age group ${ }^{3}$. This variation is due to the variable and unpredictable nature of dental trauma as well as environmental and cultural differences among countries.

The scientific literature is rich in studies concerning epidemiology, aetiology, classification and treatment of traumatic dental injuries ${ }^{4}$. The economic aspect has been given very little attention, with only four studies addressing the resources spent in the management of TDI ${ }^{5-8}$. However, there is a need to evaluate the true cost of managing dental injuries in children and adolescents in order to provide appropriate resources.

The costs of dental trauma treatment and management have been investigated by several authors in different countries ${ }^{5-8}$. Each of these studies used markedly different methodologies for costs estimation, and only Glendor et al. ${ }^{5}$ prospectively measured costs (both direct and indirect) related to TDI in children and adolescents. However, all of these studies were performed before the widespread introduction and international acceptance of the International Association of Dental Traumatology (IADT) guidelines ${ }^{9,10}$. These guidelines have standardised the acute management as well as the post-injury care and review visit protocol. It is assumed that the implementation of these guidelines would subsequently impact on the cost of acute management and the number of follow up visits after a dental injury.

The aim of this study was to estimate the total cost and number of visits required for the management of TDI in the permanent dentition in children and adolescents over a oneyear period, using prospective data from a population of children treated in a clinic that adhered to the IADT guidelines. 


\section{Material and methods}

This manuscript was written following the guidelines recommended by the Consolidated Health Economic Evaluation Reporting Standards (CHEERS) Statement.

The study was approved by the Dublin Dental School Ethics Committee, Dublin, Ireland. Children aged 6-16 years with TDI who were treated at the Dublin Dental University Hospital (DDUH) were considered for inclusion in the study. Children without confounding medical conditions and presenting with injuries to the permanent incisors were enrolled. Patients were excluded if there was a significant medical condition, lack of co-operation, poor attendance history, evidence of multiple traumatic episodes or they were receiving treatment by an undergraduate dental student.

A convenience sample of patients who fulfilled the inclusion criteria was consecutively collected. Children were divided into two age groups, using eleven years of age as a cutoff point, based on the suggestion that permanent teeth with immature root development may take more time to treat ${ }^{11}$. Injuries were broadly grouped into complex (exposure of pulp tissue and /or dislocation of tooth) and non-complex injuries (no pulp tissue exposed and no dislocation of tooth) as defined by Glendor et al ${ }^{12}$. Glendor et al. ${ }^{12}$ used the terms complicated and uncomplicated to identify two injury groups. Currently the term complicated injury is used to describe a crown or crown-root fracture where the pulp has been exposed during the injury. In this study, we have used the terms complex and non-complex to avoid any confusion in terminology. Groups were also subdivided according to the time since injury (injuries within the first year of management, injuries in the second or third year, and injuries in the fourth year and older). Only one tooth per patient was chosen for cost and time analysis. The tooth was grouped according to injury, either non-complex or complex, as well as with a specific diagnosis as shown in Table 1.

Patients attending the Trauma Clinic were seen by a team of operators with different levels of clinical expertise (general dentists, postgraduate students, and specialists). 
However, all operators were trained to use the most up-to-date IADT guidelines for diagnosis, treatment and follow-up and all patients were ultimately seen by the clinic's Consultant in Paediatric Dentistry. Radiographs were taken when clinically necessary and as per the IADT Guidelines ${ }^{9,10}$.

Direct costs included capital and overheads costs, operator and nursing staff costs, cost of dental treatment and radiographs, cost of medicine, and laboratory fees. Using pay and non-pay expenditure, the Finance Department developed an average unit cost per patient. This value was applied for all patients regardless of the length of their visit. Operator and staff costs were calculated on treatment time for routine procedures in the Trauma Clinic combined with the hourly rate for each clinical category. Treatment costs were based on the billable amount for the procedures performed in the institution. Where hospitalisation was necessary, the cost of the day case procedure under general anaesthesia was based on a retrospective analysis which estimated the cost to be $€ 689^{13}$. This cost was applied as the visit cost for those patient visits.

Indirect costs (expense of travel and childcare, and cost of missed working hours) were the non-clinical expenses paid by the parents and documented at each visit by a questionnaire. If public transport was used, the travel cost was documented by the parent via the questionnaire. When a private vehicle was used, the travel cost was calculated by multiplying the distance in kilometres with a government approved mileage rate. Data on expenses was collected from hospital records and from self-completed questionnaires prospectively at each visit. All costs were recorded in monetary values (Euros, as of December 2016) and calculated for one injured tooth per patient over one year.

A linear regression model was used to investigate the relationship between the total cost and the independent variables. The original data set did not present a parametric distribution. Therefore data transformation was used by taking the logarithm of the outcome variable (total cost, and number of visits). The log-transformed data were analysed by using the software package $\mathrm{R}$ (Version 3.3.3, www.cran.r-project.org/). For interpretation, data had to be back-transformed by taking the exponential of the total cost. 
Logistic regression analysis was used to compare non-complex and complex injuries with independent variables as well as each component of direct and indirect costs.

\section{Results}

One hundred and four patients were consecutively enrolled but nine participants failed to complete the study due to personal reasons. Ninety-five children represented by one injured tooth each, were included in the statistical analysis. The majority of the injuries (77.89\%) were complex compared to $22.11 \%$ in the non-complex group.

Table 1 identifies the frequency of non-complex and individual tooth injury diagnosis within the complex group. The most common management of the injuries included checkups and emergency visits, restoration with composite resin, apexification and root canal treatments, tooth extraction and replacement with a partial denture, among others. All treatments were performed according to the patient's needs following the IADT guidelines.

Table 2 shows the descriptive and logistic regression analysis between complex and noncomplex injuries comparing general variables (such as gender, age group and years since the injury), number of visits and each component of direct and indirect cost in Euros. Fifty-three percent of the injuries had occurred within one year, $26 \%$ were in the second or third year of management and only $20 \%$ had injuries older than 4 years.

The total costs (sum of direct and indirect costs) was $€ 1687.87$ (SD=1129.9) and $€ 1350.82$ (SD=800.6) for complex and non-complex injuries, respectively. Figure 1 represents the box plot of the indirect, direct and total costs (in Euros) of complex and non-complex injuries. The only significant differences between complex and non-complex injuries when compared to listed variables was for medication use $(p=0.03)$ as none of the patients with non-complex injuries received any prescribed medication (Table 2).

The majority of the study population had their dental injury managed in the Trauma Clinic. Only three patients $(3.1 \%)$ required hospital admission for trauma-related treatment under general anaesthesia during the study period. 
The cost analysis is detailed in Table 3 where direct and indirect costs and total costs are compared to gender, age, injury group, injury date and distance travelled to clinic. Noncomplex injuries were significantly cheaper than complex injuries $(p<0.05)$. Injuries cost significantly less $(p<0.002)$ four years after the injury when compared to the first year after injury. The total cost for treatment of a dental injury was $€ 1613.3 \pm 1071.2$ and the direct cost component was the major contributor to this expense ( $75 \%$ of the total cost).

There was no significant difference between the number of visits required for complex (5.6 visits) and non-complex (4.9 visits) injuries in the entire sample over one year ( $p$ value $=0.32$ ). There was no difference between the number of visits between first and 2-3 years. However, this number was significantly lower in year 4 onwards when compared to injuries within the first year (Table 4).

\section{Discussion}

This prospective study evaluated the range of costs associated with managing a TDI in children and adolescents, based on one injured permanent tooth per patient over one year. The IADT guidelines ${ }^{9,10}$ provide guidance for the management of TDI including a recommended periodicity for review visits. There has been no investigation on the cost of managing dental injuries since the introduction of these international guidelines. Therefore the aim of the study was to evaluate the total cost required to treat dental injuries to permanent teeth according to the IADT guidelines.

The study was completed at the Dublin Dental University Hospital which is considered as a referral centre for complex injuries, and the treatment was carried out by trained dentists in the specialised Trauma Clinic.

Many factors should be considered when analysing costs. Each study has its own setting (dental clinics, university, hospitals), local currency, transport cost, dental materials costs, and staff costs, among other factors that may influence their results. In Sweden, for example, Glendor et al. ${ }^{5}$ estimated the total societal costs of TDI in children and adolescents. Data were collected from trauma reported to an insurance company and prospectively followed-up by phone interviews over a 2-year period. The total cost 
reported was 4,569 SEK (U\$ dollars=498.2, based on Sweden prices in 1999) for dental trauma in permanent teeth. Borum and Andreasen ${ }^{8}$ investigated the cost of dental treatment for TDI in the primary and permanent dentition irrespective of the age in Denmark $^{8}$. The study involved a large cohort $(n=7945)$ of patients who had been treated for their TDI at a major trauma centre and estimated a standard per-tooth treatment cost of $\$ 926$ and $\$ 110$ for complicated and uncomplicated injuries, respectively, in the permanent dentition ${ }^{8}$. In the current study, the terms complex / non-complex were used recognising that these groups are comparable to the complicated/uncomplicated groups referred to in the literature $5,8,12$.

When comparing studies, it is important to consider which variables were reported to estimate the cost. The economic burden for replanted avulsed incisors during the first year post-injury was estimated by Nguyen et al. ${ }^{7}$ where the mean total cost of treatment was $\$ 1465 \mathrm{CAD}$, but only the direct costs were considered. On the other hand, Wong and Kolokotsa ${ }^{6}$ retrospectively examined 81 patients with 111 traumatised permanent incisors. They estimated a cost of $£ 856$ (GBP) per injured tooth per patient, but they only included the cost of outpatient care and missed working hours ${ }^{6}$. However, a more complete cost analysis was performed by Glendor et al. ${ }^{5}$ who prospectively measured costs (both direct and indirect) related to TDI in children and adolescents which was very similar to the analysis in the present study.

In all of these studies, the appointment duration was not directly measured. This could generate some bias since the time spent for each treatment will depend on several factors, such as operator experience, child behaviour, clinical setting, staff training, among others. In order to control these variables in this study, common procedures were allocated a standardized procedure time and the experience level of the operator was recorded, in order to calculate staff cost. In addition, extra visits may have been required to complete procedures where, for example, a child's behaviour was an issue.

There was no significant difference in the number of visits required for complex (mean=5.6) and non-complex (mean=4.9) injuries, contradicting previous reports where complex injuries had a significantly higher number of visits ${ }^{10,11}$. This may be explained by this estimation being based on a mix of injuries at various stages of treatment and observation periods. In the current study, some of the non-complex injuries developed 
complications over time, such as pulp necrosis and infection that required endodontic treatment, and they required a higher number of visits after the first year following the injury.

The highest number of visits occurred within the first three years following the injury in agreement with previous studies ${ }^{7,12}$. This reflects the increased monitoring required until stabilisation of the pulp and periodontal tissues. The number of visits generally reflects a high level of adherence to the IADT guidelines. However, it is noteworthy to mention that although all injuries in the Trauma Clinic were prospectively reviewed according to the IADT guidelines, the number of visits following any TDI is unpredictable. In addition, unforeseeable complications may occur and individual circumstances could influence the number of visits.

More than two thirds $(69.47 \%)$ of the children were younger than 11 years of age. Eleven years of age was used as the cut-off point between the two age groups as it has been suggested that injuries before this age are likely to need more time and higher costs because of the immature root development of the permanent incisors ${ }^{11}$. However, in the present study, no difference was found in the total cost and the number of visits between those different age groups $(p<0.05)$.

With regard to injury date, injuries older than 4 years resulted in lower costs compared to those in the earlier years. However, no difference was found between year 2-3 and the first year. This might be interpreted by the need for more definitive and complex treatment after the first year. In the current sample, decoronation, tooth replacement and active orthodontic treatment were required, which may be responsible for increasing the cost during the 2-3 years period.

As a hospital clinic, the Trauma Clinic at the DDUH receives referrals for complex injuries. Although an attempt was made to recruit non-complex injuries, the majority of the study sample comprised children referred for management of complex injuries Complex dental injuries present relatively frequently, especially in referral centres such as the DDUH and an insight into the average cost in this category of patients is valuable and essential to establish for policymakers and health institutions for the efficient allocation of resources. 
It is possible that these costs might be underestimated as they were calculated only for one tooth in each patient and it is known that dental trauma commonly includes injuries to multiple teeth. In addition, the teaching hospital fees that were used in the current estimation are significantly lower than private sector fees. The costs were estimated for one year duration which does not represent the real outcome of such complex injuries where patients with TDI are often committed to a lifetime of dental treatment. This aspect needs to be addressed in further studies. The aim of the current study was to get an estimation of the most commonly incurred direct and indirect costs. The approach adopted in this study could be reproduced and would be interesting to see comparable data from other countries.

Even though the literature on the economic cost of traumatic dental injuries is growing, no data was available in Ireland until now. The costs presented in this work are not readily comparable to previous reports in the literature due to the large time lapse and marked variation in the methodology. The data in this study are more detailed, with a reduced risk of bias due to the prospective nature of data collection. As with all cost-analyses, the results must be interpreted on their own reality and they are more likely to be useful for local application to inform policymakers and to aid the effective use of limited resources. Knowing the cost of managing TDI should be of interest to individuals, health services and to the insurance industry so that adequate resources can be planned.

In conclusion, the management of TDI in children is costly and time-consuming, with huge variations in individual costs and the number of visits required. This study showed that complex injuries are more expensive to manage than non-complex injuries, but the cost is lower in the fourth year review. The mean total cost indicated in this study (€ 1613.3 per injury over one year) suggests that a campaign to reduce the incidence of trauma could have a significant saving of resources spent in managing dental trauma. In addition, this cost estimation could be useful in the allocation of resources for a trauma service. It is important that the IADT guidelines be referenced during TDI management, but also to recognise that variations of treatment and recall visit frequency will occur on an individual basis. 


\section{References}

1. Petti S, Glendor U, Andersson L. World traumatic dental injury prevalence and incidence, a meta-analysis-One billion living people have had traumatic dental injuries. Dent Traumatol. 2018;34:71-86.

2. Lam R. Epidemiology and outcomes of traumatic dental injuries: a review of the literature. Aust Dent J. 2016;61:4-20.

3. Oldin A, Lundgren J, Nilsson M, Norén JG, Robertson A. Traumatic dental injuries among children aged 0-17 years in the BITA study-A longitudinal Swedish multicenter study. Dent Traumatol. 2015;31:9-17.

4. Azami-Aghdash S, Ebadifard Azar F, Pournaghi Azar F, Rezapour A, Moradi-Joo M, Moosavi A, et al. Prevalence, etiology, and types of dental trauma in children and adolescents: Systematic review and meta-analysis. Med J Islam Repub Iran. 2015;29:591-6.

5. Glendor U, Jonsson D, Halling A, Lindqvist K. Direct and indirect costs of dental trauma in Sweden: a 2-year prospective study of children and adolescents. Community Dent and Oral Epidemiol. 2001;29:150-60.

6. Wong FS, Kolokotsa K. The cost of treating children and adolescents with injuries to their permanent incisors at a dental hospital in the United Kingdom. Dent Traumatol. $2004 ; 20: 327-33$.

7. Nguyen PMT, Kenny DJ, Barrett EJ..Socio-economic burden of permanent incisor replantation on children and parents. Dent Traumatol. 2004;20:123-33.

8. Borum MK, Andreasen JO. Therapeutic and economic implications of traumatic dental injuries in Denmark: an estimate based on 7549 patients treated at a major trauma centre. Int J Paediatr Dent. 2001;11:249-58.

9. DiAngelis AJ, Andreasen JO, Ebeleseder KA, Kenny DJ, Trope M, Sigurdsson A, et al. International Association of Dental Traumatology guidelines for the management of traumatic dental injuries: 1. Fractures and luxations of permanent teeth. Dent Traumatology. 2012;28:2-12. 
10. Andersson L, Andreasen JO, Day P, Heithersay G, Trope M, DiAngelis AJ, et al.International Association of Dental Traumatology guidelines for the management of traumatic dental injuries: 2. Avulsion of permanent teeth. Dent Traumatol. 2012;28:88-96.

11. Borssén E, Källestal C, Holm AK. Treatment time of traumatic dental injuries in a cohort of 16-year-olds in northern Sweden. Acta Odontol Scand. 2002;60:265-70.

12. Glendor U, Halling A, Andersson L, Andreasen J, Klitz I. Type of treatment and estimation of time spent on dental trauma--a longitudinal and retrospective study. Swed Dent J.1998;22:47-60.

13. McAuliffe U, Kinirons M, Woods N, Harding M. A retrospective investigation of the oral health records of a cohort of preschool children who received extractions under general anaesthesia including cost analysis of treatment. J Ir Dent Assoc. 2017;63:3844. 
Table 1. Frequency of the various injury types groups

\begin{tabular}{lc}
\hline Injury type & Frequency \\
& $\mathbf{N}(\%)$ \\
\hline Uncomplicated crown fracture & $21(22.1)$ \\
Complicated crown fracture & $19(20)$ \\
Root fracture & $4(4.2)$ \\
Crown:root fracture & $1(1.1)$ \\
Lateral luxation/extrusion & $14(14.7)$ \\
Intrusion & $7(7.4)$ \\
Avulsion & $25(26.3)$ \\
Multiple injuries & $4(4.2)$ \\
\hline Total & $95(100)$ \\
\hline
\end{tabular}

This article is protected by copyright. All rights reserved 
Table 2. Descriptive and Logistic Regression analysis comparing general variables and costs ( $€$, Euros) and the association with complex and non-complex injuries.

\begin{tabular}{|c|c|c|c|c|}
\hline Variables & $\begin{array}{c}\text { Complex } \\
N(\%) \text { or Mean (SD) }\end{array}$ & $\begin{array}{c}\text { Non-complex } \\
N(\%) \text { or Mean (SD) }\end{array}$ & $\begin{array}{c}\text { Total } \\
N(\%) \text { or Mean (SD) }\end{array}$ & p-value \\
\hline \multicolumn{5}{|c|}{ GENERAL VARIABLES } \\
\hline \multicolumn{5}{|l|}{ Gender } \\
\hline Male (ref) & $48(80)$ & $12(20)$ & 60 & \\
\hline Female & $26(74.29)$ & $9(25.71)$ & 35 & 0.518 \\
\hline \multicolumn{5}{|l|}{ Age (years old) } \\
\hline$\leq 11$ (ref) & $53(80.30)$ & $13(19.70)$ & 66 & \\
\hline$>11$ & $21(72.41)$ & $8(27.59)$ & 29 & 0.395 \\
\hline \multicolumn{5}{|l|}{ Year } \\
\hline $0-1$ (ref) & $40(78.43)$ & $11(21.57)$ & 51 & \\
\hline $2-3$ & $18(72)$ & $7(28)$ & 25 & 0.537 \\
\hline$>4$ & $16(84.21)$ & $3(15.79)$ & 19 & 0.592 \\
\hline \multicolumn{5}{|l|}{ Distance group } \\
\hline$<25 \mathrm{~km}$ (ref) & $47(81.03)$ & $11(18.97)$ & 58 & \\
\hline $25-50 \mathrm{~km}$ & $13(76.47)$ & $4(23.53)$ & 17 & 0.680 \\
\hline$>50 \mathrm{~km}$ & $14(70.0)$ & $6(30.0)$ & 20 & 0.307 \\
\hline INDIRECT COST & $430.13(453.15)$ & $350.4(337.5)$ & $350.38(337.50)$ & 0.463 \\
\hline Travel Cost & $76.72(96.89)$ & $89.86(93.88)$ & $79.63(95.90)$ & 0.580 \\
\hline Childcare & $30.13(72.82)$ & $43.14(77.14)$ & $33.01(73.58)$ & 0.476 \\
\hline Production loss & $323.27(361)$ & $217.37(266)$ & 299.89 (343.9) & 0.217 \\
\hline DIRECT COST & 1257.72 (776.37) & $1000.4(570.65)$ & $1200.8(740.87)$ & 0.163 \\
\hline Unit Cost & $275.4(130)$ & $239(121.8)$ & $267.3(129.2)$ & 0.256 \\
\hline Nursing & $127.77(72.9)$ & $114(67.7)$ & $124.7(71.6)$ & 0.438 \\
\hline Operator & $251.43(178.9)$ & $196.6(142.2)$ & $239.3(172.3)$ & 0.202 \\
\hline Treatment & $476.4(441.2)$ & $353.1(238.1)$ & $449.15(407.3)$ & 0.227 \\
\hline Radiographs Fees & $103.24(62.2)$ & $80.95(43.11)$ & $98.31(59.04)$ & 0.130 \\
\hline Laboratory Fees & $22.29(35.27)$ & $21.66(34.54)$ & $22.15(34.93)$ & 0.941 \\
\hline Medications & $1.14(2.87)$ & $0(0)$ & $1.63(1.86)$ & $0.03^{*}$ \\
\hline
\end{tabular}

This article is protected by copyright. All rights reserved 
Table 3. Direct, indirect and total cost descriptive results and Linear Regression analysis between total cost ( $€$, Euros) and the associated factors.

\begin{tabular}{|c|c|c|c|c|c|}
\hline & DIRECT COST & INDIRECT COST & \multicolumn{3}{|c|}{ TOTAL COST ANALYSIS } \\
\hline Variables & Mean (SD) & Mean (SD) & Mean (SD) & Univariated & Ajusted Model \\
\hline \multicolumn{6}{|l|}{ Gender } \\
\hline Male (ref) & $1211.87(791)$ & $389.4(442.55)$ & $1601.3(1128.661)$ & & \\
\hline Female & $1181.9(655)$ & $452.1(410.5)$ & $1634.0(980.6)$ & 0.887 & NS \\
\hline \multicolumn{6}{|c|}{ Age (years old) } \\
\hline$\leq 11$ (ref) & $1240.4(710)$ & $413.2(385.2)$ & $1653.72(1010.38)$ & & \\
\hline$>11$ & $1110.7(812)$ & $410.73(525.26)$ & $1521.5(1212.5)$ & 0.582 & NS \\
\hline \multicolumn{6}{|l|}{ Injury Group } \\
\hline Complex (ref) & $1257.7(776)$ & $430.13(453.15)$ & $1687.8(11.29 .9)$ & & \\
\hline Non-complex & $1000.4(570)$ & $350.3(337.50)$ & $1350.8(800.6)$ & 0.205 & $0.047^{*}$ \\
\hline \multicolumn{6}{|c|}{ Distance group } \\
\hline$<25 \mathrm{~km}$ (ref) & $1080.9(650)$ & $284.07(310)$ & $1365(892.6)$ & & \\
\hline $25-50 \mathrm{~km}$ & $1309.5(510)$ & $379.24(286.94)$ & $1688.7(651.9)$ & 0.244 & 0.371 \\
\hline$>50 \mathrm{~km}$ & $1456.14(1050)$ & $813.24(579)$ & $2269.38(1510)$ & $0.001^{*}$ & $0.001^{*}$ \\
\hline \multicolumn{6}{|c|}{ Injury date (years) } \\
\hline $0-1$ (ref) & $1313.5(735)$ & $453.17(421.5)$ & 1766.7(1023.4) & & \\
\hline $2-3$ & 1318.3(817) & $527.48(507.09)$ & $1845.8(1265.7)$ & 0.751 & 0.762 \\
\hline$\geq 4$ & $743.8(444.6)$ & $152.07(184.78)$ & $895.9(512.3)$ & $0.002^{*}$ & $0.002^{*}$ \\
\hline Total & $1200.8(740.8)$ & 412.5 (429.9) & $1613.3(1071.2)$ & & \\
\hline
\end{tabular}


Table 4. Descriptive and Linear Regression (back-transformed) analysis of the number of visits and associated variables.

\begin{tabular}{lcc}
\hline Variables & $\begin{array}{c}\text { Number of visits } \\
\text { Mean (SD) }\end{array}$ & p-value \\
\hline Injury Group & $5.63(2.64)$ & \\
\hline Complex (ref) & $4.95(2.35)$ & 0.324 \\
Non-complex & & \\
\hline Injury year & $6.15(5.52)$ & 0.284 \\
\hline $0-1$ yr (ref) & $5.52(3.63)$ & $<0.001^{*}$ \\
$2-3$ yr & $3.63(1.77)$ & \\
$>4$ yr & \\
\hline Age (years) & $5.56(2.53)$ & 0.189 \\
\hline$<11$ (ref) & $5.31(2.73)$ & \\
$>11$ & $5.48(2.58)$ & \\
\hline Total &
\end{tabular}

This article is protected by copyright. All rights reserved 


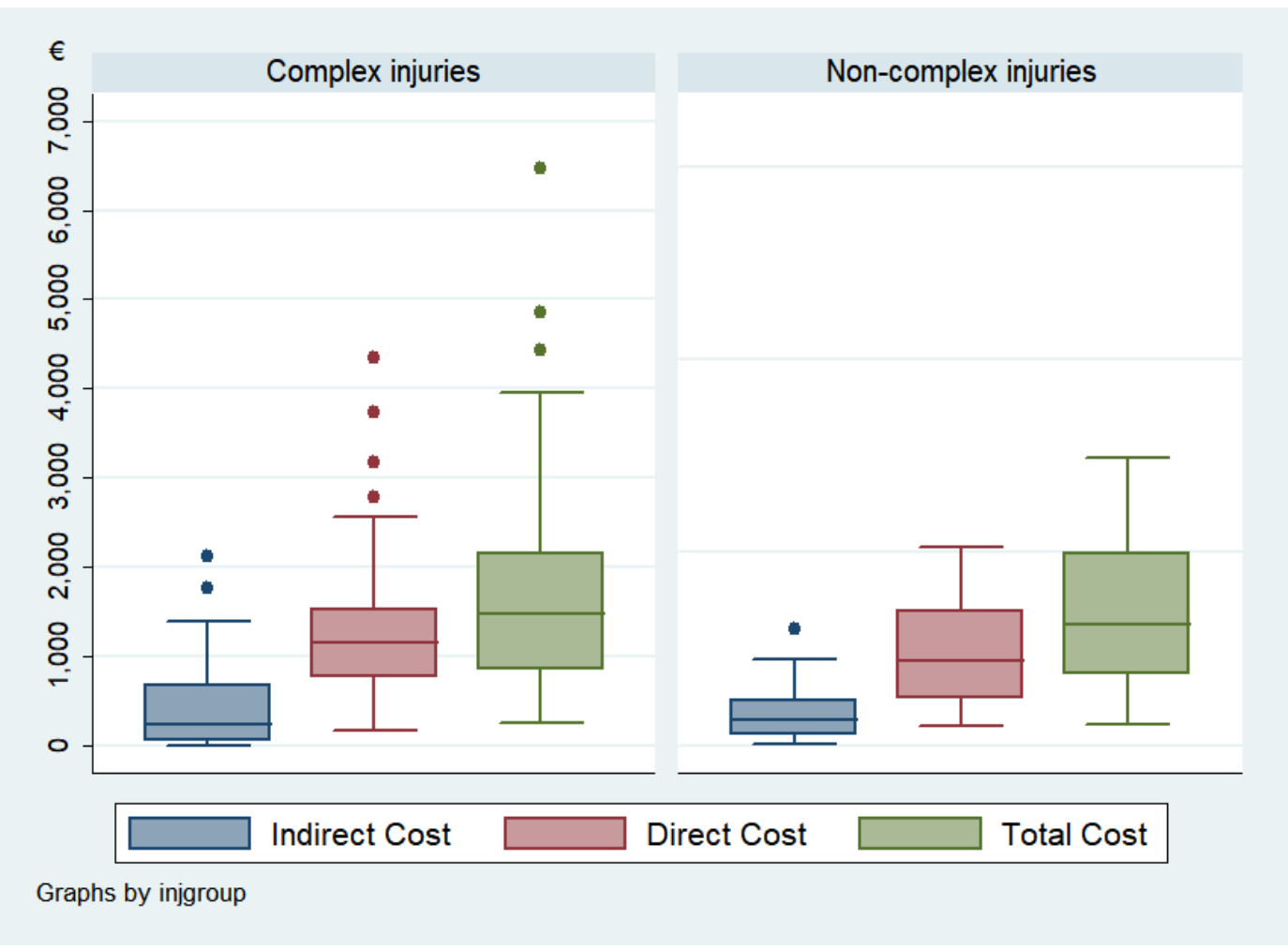

edt_12561_f1.tif

\section{Figure legend}

Figure 1: Box plot of the indirect, direct and total cost of complex and non-complex over one year (in Euros) 